\title{
ANALYSIS AND OPTIMIZATION OF SAND CASTING DEFECTS WITH THE HELP OF ARTIFICIAL NEURAL NETWORK
}

\author{
Shraban Kumar Singha ${ }^{1}$, Simran Jeet Singh ${ }^{2}$ \\ ${ }^{1}$ Master's Student, Mechanical Engineering Department, Lovely Professional University, Punjab, INDIA -144411 \\ ${ }^{2}$ Assistant Professor, Mechanical Engineering Department, Lovely Professional University, Punjab, INDIA -144411
}

\begin{abstract}
Casting defects is one and the only limitation in any casting process. Sand casting process too suffers from the same problem. Finding out the optimum condition towards acquiring minimum casting defects is very critical. The normal method that most of the companies use is the trial and error method. But due to limitations like error prone results, expensive and time consuming, this method causes too much cost to company. In this paper, an attempt has been made to minimize the casting defects by optimizing the process parameters of sand casting defect using Artificial Neural Network (ANN). The Toolbox of the MATLAB software is used to run the different values of the parameters. Parameters are selected on the basis of survey from different industry and a rigorous research of the previous paper on this topic. Before that a program was prepared in MATLAB to generate the values of different parameter by using their highest and smallest values which has been collected from a local casting industry. In our first attempt to optimize the sand casting process parameters, it is found that if we consider randomly both input and output just by considering their limits the results are satisfactory just up to a limit. And it changes if the parameters are being changed. For specific conditions the result is found to be 3.175 as casting defect. Later on a new type of program is generated based on the relation of sand casting parameters and sand casting defects. Three specific casting defects are considered called, Expansion Defect, Gas Defect, Weak sand Defect. At last, their results are found to be Expansion defect: 6.23\%, Gas Defect: 7.28\%, Weak Sand Defect: $5.74 \%$.
\end{abstract}

Keywords: Sand casting, Artificial Neural Network (ANN), MATLAB, Casting Defect

\section{INTRODUCTION}

Metal casting process is one of the oldest manufacturing method dates back to $3600 \mathrm{~B}$ C. In the earlier centuries this method was mainly used to make weapons like arrow heads, swords etc. Even though metal casting comprises of many steps but they are very easy to execute. Over the centuries human being has progressed in the field of manufacturing and invented many kinds of metal casting processes according to their requirements. Sand casting, Centrifugal casting, Injection casting, Shell mould casting and Investment casting are some of the prominent examples of metal casting processes.

Sand casting is one of the oldest and mostly used casting process of all. It is also the easiest process. In sand casting the procedure starts with the same concept like any other casting method. At first the pattern which is the replica of the end product is created with the help of machining. Then the sand mixture is created with different materials like clay, moisture, lime etc. The quality of sand casted product mostly depends on this mould mixture. Then the pattern is dipped in the mould. The dipping process differs from pattern to pattern. There are many kinds of pattern are there, viz cope and drag pattern, skeleton pattern, split pattern etc. When the cavity made by the pattern inside the mould is ready molten metal is poured and wait until the metal solidifies. As soon as the molten metal solidifies the product is taken out by breaking the sand mould. Finally the product is machined for cleaning of any kind of extra material or any kind of foreign object. Sand casting is like any other casting and has its limitation. This limitation is specifically termed as casting defect. Sand casting has many forms of casting defect and they are classified by many authors into many categories. Getting rid of these defects is impossible due to the reason that it depends on many factors of sand casting process. The only option is to minimize these casting defects as low as possible. At present casting defects are first analyzed with the help of different tools like historical data analysis, cause effect diagram, design of experiment (DOE), if-then rules etc. When the casting data are analyzed then they are used in some optimization tools like Taguchi method, or ANOVA method etc. So far these techniques are providing satisfactory results. But in the recent past the concept of simulation is growing in every sector including manufacturing industry. The concept of simulation is the trying the real process in simulated version so that we can save money and time. The Artificial Neural Network (ANN) is one of the most promising simulation techniques at present.

An Artificial Neural Network is nothing but a computational model of the human brain. Here the information's are processed with the help of some processing elements called nodes or neuron. These neurons are structured normally in three layers known as input layer, output layer and hidden layer as shown in the figure 1. The thorough details are given in the later chapters. ANN is a scientific tool which can be used in many ways. Some of them are face 
recognition, pattern recognition, optimization etc. The optimization technique is used in this thesis to optimize the conditions of the casting process parameters for optimized casting defects.

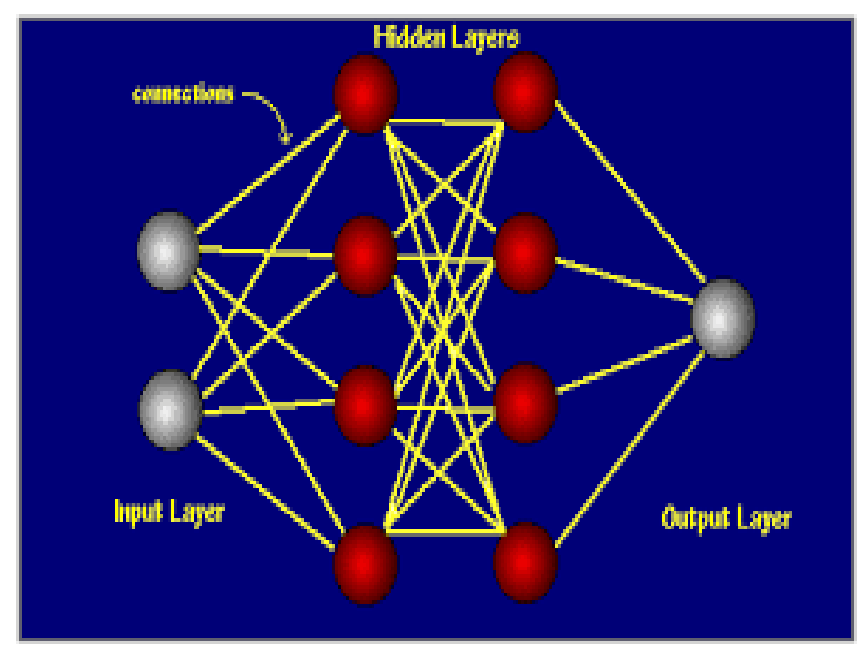

Fig -1: Graphical representation of an ANN

\section{LITERATURE REVIEW}

Metal casting process is one of the easiest manufacturing methods among all. People have been using casting process from many centuries now. In the earlier days the manufacturers or the customers didn't have to think about high accuracy or precision. In the earlier times they were only few numbers of manufacturing companies, so they didn't have to compete so much. Now a day thousands of manufacturing companies exists and so the competition is cut throat. The customers are demanding more and more accurate products at their convenient time so the companies are trying every possible means.

Rajagopalan et al. (1996) [1] studied about the mechanism of Artificial Neural Network (ANN) and its use in the world of manufacturing.. The methods, structures and applications of neural networks were presented in this paper. Yarlagadda et al. (1999) [2] studied in the area of neural network system for the prediction of process parameters in pressure die casting. In their work an artificial intelligent neural network system was developed to generate the process parameters for the pressure die casting process. They used LevenbergMrquardt approximation algorithm for this method. The accuracy of the network developed is tested by comparing the data generated from the network with that from an expert from a local die casting industry. Basheera \& Hajmeer (2000) [3] studied about the fundamentals, computing, design, and application of ANN. Sadeghi et al. (2000) [4] developed a BP-neural network predictor model for plastic injection molding process. A neural network model for predicting the quality or soundness of the injected plastic parts based on key process variables and material grade variations has been developed. Upon training of the network, its performance was tested on several sets of data taken from the simulation works on Eltex A3300 etc. Yarlagadda et al. (2001) [5] has developed a hybrid neural network system for prediction of process parameters in injection molding. The training data were generated by simulation using C-MOLD flow simulation software. A total of 114 data were collected out of which 94 were to train the network using MATLAB and the remaining 20 for testing the network. Khan et al. (2003) [6] studied the modeling of porosity defects in high pressure die casting with a neural network. The aim of the paper was to improve current modeling and understanding of defects formation in HPDC machines. They have conducted conventional die casting tests with a neural network model of HPDC machine and compared the obtained results with the current understanding of formation of porosity. They found some conflict with the previous studies of die casting. Due to the conflicts with previous results they decided that as a result it needs more investigation. S. Guharaja et al. (2004) [7] analyzed the various process parameters of the green sand casting process. They made an attempt to reach optimal settings of green sand casting process in order to acquire the optimum quality characteristics of the spheroidal graphite (SG) cast iron rigid coupling castings. Ultimately they considered the four most prominent parameters and they were green strength, mould hardness, moisture content and permeability. The effect of the selected process parameters and its effect on different level on casting defects were optimized using Taguchi's optimization approach. Chandran et al. (2009) [8] researched in the area of optimization of process parameters to minimize the casting defects and found out how to minimize the casting defects such as, sand drop, sand blow holes, scabs, pinholes. He used Taguchi method to optimize and the parameters considered are moisture content $(\%)$, green strength $(\mathrm{g} / \mathrm{cm} 2)$, mould hardness, sand practical size (AFS). In his research he realized the optimum conditions of taken parameters as follows Moisture (\%) - level 2 - 3.8 Green Strength $(\mathrm{g} / \mathrm{cm} 2)$ - level 2 - 1400 Sand Particle Size (AFS) - level 1 - 50 Mould Hardness $(\mathrm{Nu})$ - level 3 - 75. Vosniakos et al. (2009) [9] studied in the field of the scope of artificial neural network metamodels for precision casting process planning. In this paper the researchers tried to optimize the precision casting process by using computer simulating software's using 'what if' scenarios. Simulation results cannot help the engineers for work pieces other than the one simulated product. In this paper a series of feed forward artificial neural network (ANN) models is presented aiming at such generalization. Zheng et al. (2009) [10] studied optimization of high-pressure die-casting process parameters using artificial neural network. They found that high pressure die casting process has many attributes involved which contribute to the complexity of the process. It is essential for the engineers to optimize the process parameters and improve the surface quality. They considered mold temperature, pouring temperature, and injection Velocity are as the parameters for the network. It was found that the trained network has great forecast ability. Mane et al. (2010) [11] researched about a new approach to casting defects classification and analysis supported by simulation. They discussed about the different problems that the manufacturing industry mainly casting industry is facing till now even though the technology now a days is beyond imagination. They mentioned that global buyer demands 
defect free castings and strict delivery schedule, which foundries are finding it very difficult to meet. At last they summarized showing all the measures the researchers taking all over the world to overcome the existing casting defects. Wisam M. Abu Jadayil (2011) [12] researched in studying the effects of varying the pouring rate on the casting defects using nondestructive testing techniques Then Al casting samples have been prepared with different pouring rate for each. Then they have been tested using the penetrant test (PT) and the ultrasonic test (UT) to describe the surface and subsurface defects respectively. It was found that when the pouring rate increases surface defects are significantly increases as the penetrant testing results showed Igor Gresovnik (2012) et al. [13] had applied the Artificial Neural Network (ANN) to improve steel production process. They tried to optimize the steel production by optimizing the process parameters of different processes of steel production such as continuous casting. First it was intended only to use in the production of carbon nano materials in arc discharge reactors. Then it was generalized for other purposes too. Ganesh G. Patil et al. (2014) [14] reviewed about the improvement of casting process with the help of Artificial Neural network (ANN). They realized that industry generally tries to eliminate the defects by trial and error method, which is an expensive and error-prone process. This paper presents review on a use of Artificial neural network (ANN) for the casting processes better than the other techniques such as design of experiment (DOE), inspection method, casting simulation, cause-effect diagram, genetic algorithm, fuzzy logic. They discussed about the challenges faced by ANN method in the area of prediction, optimization, control, monitor, identification, classification, modeling and so on particularly in the field of manufacturing. The also discussed about the number of key issues which should be addressed while applying neural network to practical problems.

\section{IMPLEMENTATION OF ANN}

Neural Networks are the artificial representation of biological neurons of human brain. This neuron system is circulated in parallel around processing system. These neurons are highly interconnected among them and have the ability learn from real life experiences and adapt information's and make it available for future use. Several learning methods are available to enable the $\mathrm{NN}$ to acquire knowledge. NN architectures are classified into many types. Some NN refers their learning process as training. Neural Networks are simply imitations of human brains central nervous system and they are designed to act more and more like a human brain. A human brain has billions of nodes termed as neurons which are capable of performing computations like cognition, logical inference or pattern recognition. For example a human brain can distinguish between two persons though the two people have the same features physically. So a NN is nothing but imitation of human brain and that is why these NNs are called Artificial Neural Network (ANN).

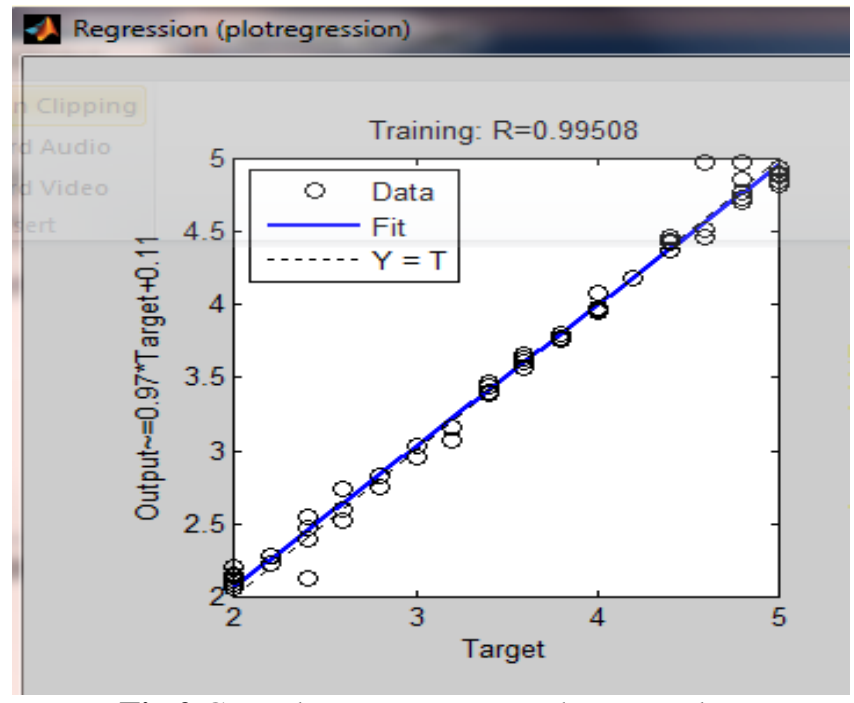

Fig 2 Curve between output and target value

Implementation of ANN to optimize the sand casting defects is one of the modern techniques used in industries now a day. Prediction of the most optimized conditions for defect free casting is nearly impossible. But all it can be done is minimizing the casting defects as low as possible. Artificial Neural Network has many forms of algorithms but the most common and famous for optimization is the back propagation algorithm. In back propagation process first the input weights are given randomly and a target is been set. When the program runs it gives outputs and accordingly the network shows the error between the output and the set target values and the Network corrects itself continuously until the network exceeds the minimum error goal possible. A several amount of data which is been used in optimizing the casting defect problem were collected from a local industry call Ajay casting and forging. In total eight number of process input parameter were selected on the basis of thorough literature survey on this specific area and also on the expertise of the engineers working on the industries form a very long time. The output parameter was termed as casting defect. The higher and the lower limits of all the process parameter and the output parameter were collected from the casting company and different research papers. All the input parameters are given as per the table 1.

Table -1: Different sand parameters and their values

\begin{tabular}{|l|l|l|l|l|}
\hline $\begin{array}{l}\text { Sl. } \\
\text { No. }\end{array}$ & Name & Unit & $\begin{array}{l}\text { Lower } \\
\text { value }\end{array}$ & $\begin{array}{l}\text { Higher } \\
\text { Value }\end{array}$ \\
\hline 1. & Moisture content & $(\%)$ & 3 & 5 \\
\hline 2. & Permeability & AFs & 120 & 190 \\
\hline 3. & Loss on Ignition & $(\%)$ & 3 & 5 \\
\hline 4. & $\begin{array}{l}\text { Compressive } \\
\text { strength }\end{array}$ & $\left(\mathrm{Kg} / \mathrm{cm}^{2}\right)$ & 1 & 1.45 \\
\hline 5. & Volatile Content & $(\%)$ & 2 & 3.5 \\
\hline 6. & Vent Holes & $(\mathrm{No})$. & 7 & 10 \\
\hline 7. & Pouring Time & $(\mathrm{Sec})$ & 44 & 48 \\
\hline 8. & Mould Pressure & $\left(\mathrm{Kg} / \mathrm{Cm}^{2}\right)$ & 4.5 & 7 \\
\hline
\end{tabular}


After the input process parameters has been chosen and the higher and lower limits of their value in specific unit has been registered then the final work starts for ANN. At first a program was developed depending on the higher and lower limit values of the process parameters using the following formula

$$
\boldsymbol{X}_{i}=\boldsymbol{X}_{\boldsymbol{i}}{ }^{L}=\frac{\left(\boldsymbol{X}_{\boldsymbol{i}}{ }^{U}-\boldsymbol{X}_{\boldsymbol{i}}{ }^{L}\right)}{\left(\mathbf{2}^{n}-\mathbf{1}\right)} *(\text { Decoded value of string })
$$

Where, $\mathrm{X}_{\mathrm{i}}$ = Value of the parameter,

$\mathrm{X}_{\mathrm{i}}^{\mathrm{U}}=$ Upper limit value of the parameter

$\mathrm{X}_{\mathrm{i}}^{\mathrm{L}}=$ Lower limit value of the parameter

$\mathrm{n}=$ Number of bits.

The data is first generated in the MATLAB with the help of the aforementioned program. Then the data is stored in the workspace of the ANN tool of the MATLAB. At first minimum of 100 sets of input and target values are generated on a trial basis. A network is created as shown in the figure 2 in the $\mathrm{NN}$ function of the ANN tool in MATLAB software. The input and target values are provided to the network from the data stored in workspace. Network starts calculating by comparing the input values with the target values and by passing the weighted inputs to the nodes of the first layer. The outputs produced are passed on to the set of target values and it goes on and on until the nodes of the output layer compute the final outputs.

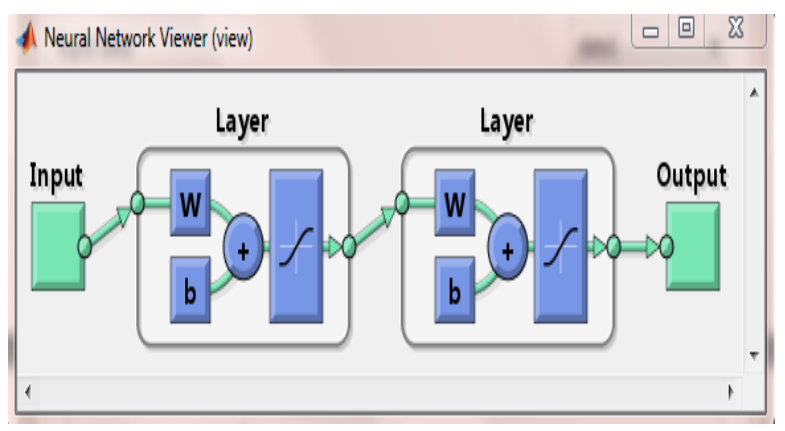

Fig -3: Physical view of the created neural network

The training and testing of a newly prepared network as shown in figure 3 is heavy duty work and it takes time. The aforementioned 8 parameters are fed as input parameters and output parameter was given as casting defect in percentage as collected from the company. In this paper when data generation was complete they were stored in the workspace for easy access. As shown in the following a network is created by putting the data stored in the workspace. Then the network was trained using the parameter values. At first a network is created with two hidden layer and sigmoidal function as their activation function. At first the learning rate is given at minimum 0.1 and in one go 1000 iterations are considered.

\section{RESULTS AND DISCUSSION}

To optimize the sand casting process parameters for minimum casting defect the data were generated randomly by providing a higher limit and lower limit of the process parameters and applying a normalization formula which was shown earlier. After few thousand iterations in ANN toolbox in MATLAB, results are found. The results are applicable to some extent for a specific number of data. But, when we change the numbers of process parameter values the optimum casting defect in percentage fluctuates by a great deal, which is not acceptable.

Table 2: Optimum sand casting defect

\begin{tabular}{|c|c|c|c|c|}
\hline \multicolumn{4}{|c|}{ Optimum input process parameters } & casting \\
\hline 1 & $\begin{array}{l}\text { Moisture } \\
\text { content }\end{array}$ & $\%$ & 4.73 & \multirow{8}{*}{$3.17 \%$} \\
\hline 2 & Permeability & AFS & $\begin{array}{l}166 . \\
7\end{array}$ & \\
\hline 3 & $\begin{array}{ll}\text { Loss } & \text { on } \\
\text { Ignition } & \\
\end{array}$ & $\%$ & 4.2 & \\
\hline 4 & Green strength & $\underset{2}{\mathrm{Kg} / \mathrm{cm}}$ & 1.42 & \\
\hline 5 & $\begin{array}{l}\text { Volatile } \\
\text { Content }\end{array}$ & $\%$ & 3.4 & \\
\hline 6 & Vent Holes & No. & 11 & \\
\hline 7 & Pouring Time & $\mathrm{Sec}$ & 47.2 & \\
\hline 8 & $\begin{array}{l}\text { Mould } \\
\text { Pressure }\end{array}$ & ${ }_{2} \mathrm{Kg} / \mathrm{cm}$ & 5.83 & \\
\hline
\end{tabular}

It is concluded after the first trial that the results are suitable only for specific type of material and conditions. As per the data provided by the local casting manufacturing company namely, Ajay casting and forging company following is the first set of results as shown in the table 2 .

Later on a new idea of finding out a temporary relationship among the considered process parameter and a specific kind of defect is generated by keeping few parameters as constant. In this equations process parameters are related to this specific casting defect casting process are considered. There are the few casting defects which were considered and they are shown below:

1. Expansion defects.

2. Gas defect.

3. Weak sand defect.

After many considerations out of that eight, five sand casting process parameters are selected for the development of the temporary equations which relates the casting process parameters and different casting defects.

1. Moisture content $\left(\mathrm{M}_{\mathrm{C}}\right)$.

2. Permeability $(\mathrm{P})$.

3. Pouring temperature $\left(\mathrm{P}_{\mathrm{T}}\right)$.

4. Green compression strength $\left(\mathrm{G}_{\mathrm{S}}\right)$.

5. Number of vent holes $\left(\mathrm{N}_{\mathrm{V}}\right)$.

Out of the five parameters three terms are considered as constants since these parameters has very low impact on the specific casting defect. These values of parameter are crucially consulted with company experts and verified with all previous research. They are as follows 
1. Pouring temperature $\left(\mathrm{P}_{\mathrm{T}}\right)=1400^{\circ} \mathrm{C}$.

2. Permeability $(\mathrm{P})=180(\mathrm{AFS} /$ unit $)$

3. Green Compression strength $\left(\mathrm{G}_{\mathrm{S}}\right)=2.2418 \mathrm{Kg} / \mathrm{cm}^{2}$

The defects and the process parameters are equated in the following way

$$
\operatorname{Min}(\mathbf{f})=\left(\mathbf{M}_{\mathrm{C}}, \mathbf{P}, \mathbf{P}_{\mathrm{T}}, \mathbf{G}_{\mathrm{S}}, \mathbf{N}_{\mathrm{V}}\right)
$$

Where $\mathrm{f}=$ Function denoting casting defect.

$\mathrm{M}_{\mathrm{C}}=$ Moisture content

$\mathrm{P}=$ Permeability .

$\mathrm{P}_{\mathrm{T}}=$ Pouring temperature.

$\mathrm{G}_{\mathrm{S}}=$ Green compression strength

$\mathrm{N}_{\mathrm{V}}=$ Number of vent holes.

Table -3: Final Results

\begin{tabular}{|c|c|c|c|c|c|}
\hline \\
\hline $\begin{array}{l}\text { Sl. } \\
\text { N } \\
\text { o. }\end{array}$ & $\begin{array}{l}\text { Output } \\
\text { Optimu } \\
\mathrm{m} \\
\text { Casting } \\
\text { Defect }\end{array}$ & Value & $\begin{array}{l}\text { Input } \\
\text { Optimum } \\
\text { Parameter }\end{array}$ & Unit & Value \\
\hline \multirow{5}{*}{1.} & \multirow{5}{*}{$\begin{array}{l}\text { Expansi } \\
\text { on } \\
\text { Defect }\end{array}$} & \multirow{5}{*}{$6.23 \%$} & $\begin{array}{l}\text { Moisture } \\
\text { content }\end{array}$ & $\%$ & 3.67 \\
\hline & & & Permeability & AFS & 180 \\
\hline & & & $\begin{array}{l}\text { Pouring } \\
\text { temperature }\end{array}$ & $\mathrm{K}$ & 1400 \\
\hline & & & $\begin{array}{l}\text { Green } \\
\text { compression } \\
\text { strength }\end{array}$ & $\mathrm{Kg} / \mathrm{cm}^{2}$ & 2.242 \\
\hline & & & $\begin{array}{l}\text { Number of } \\
\text { vent holes }\end{array}$ & $\begin{array}{l}\text { Numbe } \\
\text { rs }\end{array}$ & 9 \\
\hline \multirow{5}{*}{2.} & \multirow{5}{*}{$\begin{array}{l}\text { Gas } \\
\text { Defects }\end{array}$} & \multirow{5}{*}{$7.28 \%$} & $\begin{array}{l}\text { Moisture } \\
\text { content }\end{array}$ & $\%$ & 4.12 \\
\hline & & & Permeability & AFS & 180 \\
\hline & & & $\begin{array}{l}\text { Pouring } \\
\text { temperature }\end{array}$ & $\mathrm{K}$ & 1400 \\
\hline & & & $\begin{array}{l}\text { Green } \\
\text { compression } \\
\text { strength }\end{array}$ & $\mathrm{Kg} / \mathrm{cm}^{2}$ & 2.242 \\
\hline & & & $\begin{array}{l}\text { Number of } \\
\text { vent holes }\end{array}$ & $\begin{array}{l}\text { Numbe } \\
\text { rs }\end{array}$ & 11 \\
\hline \multirow{5}{*}{3.} & \multirow{5}{*}{$\begin{array}{l}\text { Weak } \\
\text { Sand } \\
\text { Defects }\end{array}$} & \multirow{5}{*}{$5.74 \%$} & $\begin{array}{l}\text { Moisture } \\
\text { content }\end{array}$ & $\%$ & 3.9 \\
\hline & & & Permeability & AFS & 180 \\
\hline & & & $\begin{array}{l}\text { Pouring } \\
\text { temperature }\end{array}$ & $\mathrm{K}$ & 1400 \\
\hline & & & $\begin{array}{l}\text { Green } \\
\text { compression } \\
\text { strength }\end{array}$ & $\mathrm{Kg} / \mathrm{cm}^{2}$ & 2.242 \\
\hline & & & $\begin{array}{l}\text { Number of } \\
\text { vent holes }\end{array}$ & $\begin{array}{l}\text { Numbe } \\
\text { rs }\end{array}$ & 8 \\
\hline
\end{tabular}

All the parameters have their specific values at specific conditions. While configuring the equations of defects and the parameters few parameters are again selected which has less effect on the specific casting defect and therefore they are considered as constraints. Remaining terms are put to the equations as per their relation with that casting defect. When the equations are prepared for all 3 kinds of defects there is always 2 or 3 parameters are used as variables and when the equations are applied in the previous program these variable vary from their lower value to higher value. At the same time the targeted values also generated according to the relationship.

When the data are generated and they are applied in the network created in the ANN toolbox of MATLAB the network starts training to achieve the optimum condition for the output result. In this case it is to minimize the output value as low as possible since the result is sand casting defect. The output result and the related optimizing conditions are given below in the tabulated form as shown in the Table 3.

\section{CONCLUSION}

It is been established that Artificial Neural Network has many applications. Among them, face recognition; pattern recognition and optimization are the most important ones. To use ANN in optimization of sand casting defect first we need to consider the parameters. At first the aforementioned eight parameters are selected and the program is run and the data was generated. Then the generated data are applied in the ANN toolbox in MATLAB. The results are coming one by one but still not satisfactory since ANN takes time. At first trial the results were not so satisfactory but as the training continued it was better. The ultimate goal behind the trainings is to minimize the Mean square Error (MSE). The program is generated using MATLAB. Along the way it is been modified many times to improve the outcomes. Theoretically speaking the outcome of the last training is much more reliable than the previous one. In the final program few parameters like pouring temperature, Green compressive strength etc. are considered as constant and some fixed values are used. Then a relation is established between casting defects and parameters. Three specific kinds of sand casting defect are selected for this approach. Ultimate results of the defects are found as, Expansion defect $\left(D_{\text {Exp }}\right)=6.23 \%$, Gas defect $\left(D_{\text {Gas }}\right)=7.28 \%$, Weak sand defect $\left(\mathrm{D}_{\mathrm{WS}}\right)=5.74 \%$ validating the methodology adopted for this work as the results are similar to the previous results available from experiments conducted by Taguchi. From these validation it is concluded that minimization of the casting defect percentages is possible with the help of ANN.

\section{ACKNOWLEDGEMENTS}

I am profoundly grateful to my respected supervisor Mr. Simran Jeet Singh, Assistant Professor, Department of Mechanical Engineering, LPU, Punjab for his constant involvement, energetic efforts and proficient guidance. 


\section{REFERENCES}

[1] Alfred T. Spada, Ramesh Rajagopalan and Purnima Rajagopalan, (1996), “Application of Neural Network in manufacturing" The $29^{\text {th }}$ annual Hawaii International Conference on system sciences. P. 132141.

[2] Prasad K.D.V. Yarlagadda, Eric Cheng Wei Chiang, (1999), "A neural network system for the prediction of process parameters in pressure dies casting", Journal of Materials Processing Technology, vol. 89-90, pp. 583-590.

[3] I.A. Basheera, M. Hajmeer, 2000, “Artificial neural networks: fundamentals computing, design, and application", Journal of Microbiological Methods, 43, pp. 3-31.

[4] B.H.M. Sadeghi, (2000) "A BP-neural network predictor model of plastic injection molding process" Journal of Materials Processing Technology, vol. 103, pp. 411-416.

[5] Prasad K.D.V. Yarlagadda, Cobby Ang Khong, 2001 "Development of hybrid neural network system for prediction of process parameters in injection molding", Journal of Materials Processing Technology", vol.118, pp.-8

[6] M. Imad Khan, Yakov Fray man and Saeid Nahavandi, (2003) "Modeling of porosity defects in High pressure die casting with a neural network", CRC for Cast Metals Manufacturing.

[7] S. Guharaja, A. Noorul Haq, K. M. Karuppannan, (2011) "Optimization of green sand casting process parameters and defects by using Taguchi's method" The International Journal of Advanced Manufacturing Technology, Volume 55, Issue 1-4, pp. 23-34.

[8] Udhaya Chandran. R.M, (2009) "optimization of process parameters to minimize the casting defects" International Journal of Advances in Engineering Science and Technology pp. 105

[9] G.C. Vosniakos, V.Galiotou, D.Pantelis , P. Benardos , P.Pavlou, (2009) "The scope of artificial neural network meta models for precision casting process planning" Robotics and Computer-Integrated Manufacturing, vol. 25, pp. 909-916.

[10]Jiang Zheng, Qudong Wang, Peng Zhao, Congbo Wu, (2009), "Optimization of high-pressure die-casting process parameters using artificial neural network" The International Journal of Advanced Manufacturing Technology, Vol. 44, Issue 7-8, pp. 667-674.

[11] V.V.Mane, Amit Sata and M. Y. Khire, (2010), "New Approach to Casting Defects Classification and Analysis Supported by Simulation", vol. 13 pp. 231-242.

[12] Wisam M. Abu Jadayil, (2011), "Studying the Effects of Varying the Pouring Rate on the Casting Defects Using Nondestructive Testing Techniques", Vol. 5, pp. $521-526$.

[13] Igor Gresovnik, Tadej Kodelja, Robert Vertnik, Bzidar Sarler, (2012) "Application of artificial neural networks to improve steel production process"
Proceedings of the International Conference Artificial Intelligence and Soft Computing.

[14] Ganesh g. Patil, Dr. k. h. Inamdar, "Prediction of casting defects through Artificial Neural Network", 2014, Vol. 02 Issue 05, pp. 245-253.

[15] S.S. Jamkar, M.J.Deshmukh, N.A. Vidhate, (2014)"optimization of green sand casting process parameter by Taguchi method: a review", International Journal of Mechanical Engineering, Volume 4 Issue 1.

[16] Sunil Chaudhary and Hemant Thakkar, (2014) "Review on Analysis of Foundry Defects for Quality Improvement of Sand Casting" Journal of Engineering Research and Applications, Vol. 4, Issue 3, pp.615-618.

[17] Vivek S. Gondkar, K .H. Inamdar, (2014) " Optimization of Casting Process Parameters through Simulation" International Journal of Application or Innovation in Engineering \& Management, Vol. 3, Issue 6, pp. 276-284. 